\title{
Chemical Properties and Nutrient Loadings of Rainwater during Farming Season
}

\author{
Min-Kyeong Kim, Seong-Chang Hong*, Jong-Sik Lee, Goo-Buk Jung, Soon-Ik Kwon, \\ Mi-Jin Chae, Sun-Gang Yun, and Kyu-Ho So \\ National Academy of Agricultural Science(NAAS), RDA, 150 Suin-ro, Suwon 441-707, Republic of Korea.
}

(Received: October 2 2013, Accepted: October 15 2013)

Recently, special attention has been given to acid rain and its problem to environment such as acid precipitation and air pollution in East Asia. In the present study, rainwater samples were collected from Apr to Nov in 2012. The samples were chemically characterized for the assessment of emission sources. Suwon and Yeoju regions, typical agricultural areas in South Korea, were chosen for study sites. Ion composition and cation-affected neutralization were determined to evaluate the contribution of cations to the acidity of rainwater. Ion and electrical conductivity between the measured and the estimated showed high correlation. The cations observed in Suwon and Yeoju were $\mathrm{Na}^{+}>\mathrm{NH}_{4}{ }^{+}>\mathrm{K}^{+}>\mathrm{Ca}^{2+}>\mathrm{Mg}^{2+}>\mathrm{H}^{+}$and $\mathrm{Na}^{+}>\mathrm{K}^{+}>\mathrm{NH}_{4}{ }^{+}>$ $\mathrm{Ca}^{2+}>\mathrm{Mg}^{2+}=\mathrm{H}^{+}$, respectively. The anions of all sites were $\mathrm{SO}_{4}{ }^{2-}>\mathrm{NO}_{3}{ }^{-}>\mathrm{Cl}^{-}$. While the amounts of sulfate, one of the major dissolved components of rainwater, were 77.6 and 75.6 ueq $\mathrm{L}^{-1}$ in Suwon and Yeoju, the ones of NSS-SO ${ }_{4}{ }^{2-}$ (Non-Sea Salt sulfate) were 83 and $82 \%$ in Suwon and Yeoju, respectively. The comparison of observed $\mathrm{pH}$ values $\left(\mathrm{pH}_{\mathrm{obs}}\right)$ with the theoretical $\mathrm{pH}$ values $\left(\mathrm{pH}_{\text {the }}\right)$ showed that the neutralization of rain water considerably went along during the study periods. The highest amounts of rainfall throughout the year in Suwon and Yeoju were 572.3 and $\mathbf{4 8 4 . 6} \mathrm{mm}$ in July, and its corresponding nitrogen loadings in Suwon and Yeoju were 5.28 and $3.50 \mathrm{~kg} \mathrm{ha}^{-1}$, respectively. The major ion contents for crop growth with $\mathrm{SO}_{4}{ }^{2-}, \mathrm{Ca}^{2+}, \mathrm{K}^{+}$ and $\mathrm{Mg}^{2+}$ were 51.7, 5.2, 11.8 and $1.8 \mathrm{~kg} \mathrm{ha}^{-1}$ in Suwon and 34.2, 4.0, 4.2 and 1.1 $\mathrm{kg} \mathrm{ha}^{-1}$ in Yeoju.

Key words: Acidity, Discharge, Nutrient, Rainwater
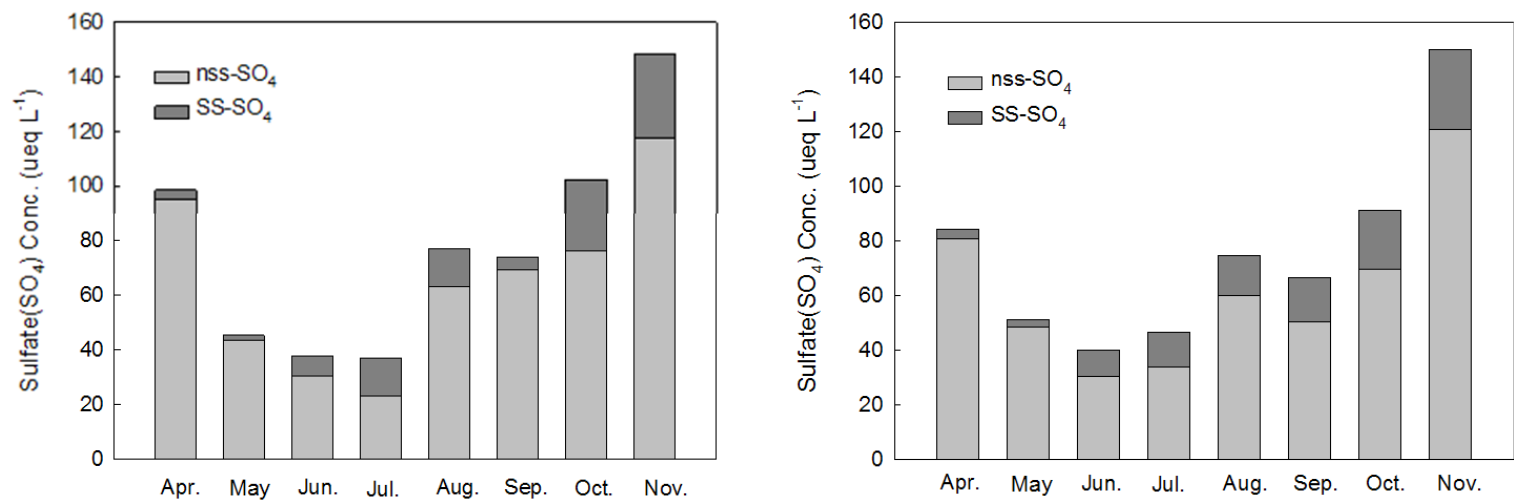

Monthly changes of sulfate contents of rainwater collected at Suwon (left) and Yeoju (right) in 2012.

\footnotetext{
*Corresponding author : Phone: +82312900224, E-mail: schong@korea.kr

${ }^{\S}$ Acknowledgement: This study was carried out with the support of "Research Program for Agricultural Science \& Technology Development (Project No. PJ008507)”, National Academy of Agricultural Science, Rural Development Administration, Republic of Korea.
} 


\section{Introduction}

최근 이상기상과 환경오염이 심해지면서 농업환경자원 보호에 대한 필요성이 강조되고 있고 국가 환경 안보 측면 에서 극심한 기후변화에 따른 환경 관리전략을 수립하는 것 이 사전 예방적인 대응 전략으로 강조되고 있다 (Murdoch et al., 2000). 따라서 선진국에서는 급속한 산업화로 인한 환경오염도 평가에서 인위적인 유래로 기인된 대기침적 및 산성비 등 강우에 의한 대기 오염도 평가 등에 관심을 집중 하고 있다 (Chudaeva et al., 2006; Wang et al., 2007).

강우는 대기로부터 오염물질들을 정화하는 중요한 기작 (Scorer, 1994)으로 대기 중으로 배출되는 여러 물질은 자연 적인 요인으로 육지 및 바다에서 유래되며 방출과 산불, 지 질운동, 바람에 의한 먼지 등의 요인이 있다. 인위적인 요인 으로 인간의 일반적 생활과 산업 활동 과정에서 발생되는 데, 구름 내에서의 세정작용과 강우 시 흡수와 흡착 과정에 서 산성비가 생성된다 (Chudaeva et al., 2006; Cheng et al., 2011; Park et al., 2000). 산성비의 영향은 풍향과 풍 속에 따라 차이는 있으나 장거리 이동으로 오염원으로부터 떨어져 있는 주변 국가에도 직접 또는 간접으로 영향을 주 는 등 그 피해가 광범위하다 (Charron et al., 2000). 작물 과 토양 및 지표수는 비, 눈 또는 안개 등의 습식침전물, 그 리고 가스와 미세입자와 같은 건식침전물의 형태로 강하되 는 화학성분들의 영향을 받는다. 산성비의 영향으로는 산림 이나 농작물 (Rinallo, 1992), 토양 및 미생물 (Wang et al., 2010), 하천 및 호수 (Cronan and Schofield, 1979), 건축물 (Contardi et al., 2000; Okochi et al., 2000) 인체에 대한 피해 (Peart, 2000) 등이 알려져 있다.

우리나라의 경우에는 지리적으로 북반구의 중위도 극동 지역에 위치하여 산성비에 의한 뚜렷한 대규모 피해지역이 아직은 없으며 우리나라와 같은 중위도에 있는 서유럽의 국 가들과 달리 우리나라는 월별 강우량 변화가 크고 대기 중 알카리 성분들에 의해 강우의 산성도가 크게 중화되는 특성 을 지니고 있다 (Lee et al., 1999; 2004; 2009; Ko et al., 2010). 그러나 우리나라는 최근 급속한 산업화로 많은 양의 아황산가스를 배출하고 있는 중국의 동쪽에 위치하고 있으 며 편서풍 영향 하에 위치한 지리적 여건으로 강우의 산성 도 등 이화학적 특성과 관련하여 지속적으로 모니터링을 실 시 할 필요가 있다.

따라서, 본 연구는 이상기상이 빈번한 기후변화 시대에 강우의 화학적 특성이 농업환경에 미치는 영향을 예측하기 위한 기초자료를 얻기 위하여 영농기를 중심으로 농업지역 인 수원과 여주지역 강우의 화학적 특성과 부하량을 평가하 였다.

\section{Materials and Methods}

도시인근 농업지역인 경기도 수원시 서둔동 국립농업과 학원 $\left(37^{\circ} 16^{\prime} 28.72^{\prime \prime} \mathrm{N}, 126^{\circ} 59^{\prime} 10.53^{\prime \prime} \mathrm{E}\right)$ 과 경기도 여주군 능 서면 오계2리 마을회관 $\left(37^{\circ} 16^{\prime} 32.22^{\prime \prime} \mathrm{N}, 127^{\circ} 35^{\prime} 21.32^{\prime \prime} \mathrm{E}\right)$ 에 각각 설치된 강수 자동 채취기를 이용하여 2012년 영농기간
중 빗물을 채수하였다.

조사된 시료 수는 2012년 4월부터 11월까지 8개월간 수 원 32 점과 여주 20 점을 채수하였다. 빗물 채취는 bulk sampling 방식으로 매 강우마다 채수하였으며, 센서에 강수 가 감지되면 자동으로 뚜껑이 열려 빗물을 채수하는 Wet sampling 방식의 강수 자동채취기 (SL12021, Shinill Science Co., Korea)를 사용하였다. 빗물의 화학성분은 수질오염공 정시험법 (MOE, 2011)과 Standard Method (APHA, 1998)에 준하여 분석하였다. $\mathrm{pH}$ 와 $\mathrm{EC}$ 는 각각 ion analyzer (EA 940, Orion, USA)와 conductivity meter (Model 162, Orion, USA)를 사용하여 측정하였다. $\mathrm{NH}_{4}{ }^{+}$는 Indophenol blue법, $\mathrm{SO}_{4}{ }^{2-}$ 는 $\mathrm{BaCl}_{2}$ 에 의한 비탁법, $\mathrm{NO}_{3}{ }^{-}$는 자외선 흡광광도법, $\mathrm{Cl}^{-}$은 치오시안산 제 2 수은법으로 정량하였으며, 기타 양이 온들은 ICP (GBC Integra XMP, Australia)를 이용하여 측 정하였다.

조사된 강우의 산성도 중화를 평가하기 위하여 측정 $\mathrm{pH}$ 와 기존 보고 (Galloway et al., 1987)에 의해 구한 이론 $\mathrm{pH}$ 값 $\left(\mathrm{pH}_{\text {the. }}\right)$ 을 비교하였다. 이때 이론 $\mathrm{pH}$ 값인 $\left(\mathrm{pH}_{\text {the. }}\right)$ 은 $-\log \left(\left[\mathrm{H}^{+}\right]+\left[\mathrm{NH}_{4}^{+}\right]+\left[\mathrm{Ca}^{2+}\right]\right)$ 로 구하였다.

\section{Results and Discussion}

2012년 조사기간 중 월별 강우량 변화는 Fig. 1 과 같다. 2012년 수원과 여주의 총 강우량은 각각 1,748 과 $1,559 \mathrm{~mm}$ 로 여주에 비해 수원이 많았으며 조사기간인 4월부터 11월 의 수원과 여주의 강우량은 총 강우량의 $94.2 \%$ 와 $93.1 \%$ 를 차지하였다. 또한 조사기간 중 월별 강우량은 수원과 여주 모두 7월에 가장 많았으며 영농초기인 5 월에 가장 적었다.

강우의 화학적 조성은 산성도 원인물질 및 중화에 미치 는 요인 구명에 중요하다. 이러한 화학적 특성을 알아보기 위하여 전체 이온함량에 대한 각 이온의 구성비는 Table 1 과 같다. 수원과 여주의 강수 중 양이온 구성은 각각 $\mathrm{Na}^{+}>$ $\mathrm{NH}_{4}^{+}>\mathrm{K}^{+}>\mathrm{Ca}^{2+}>\mathrm{Mg}^{2+}>\mathrm{H}^{+}$와 $\mathrm{Na}^{+}>\mathrm{K}^{+}>\mathrm{NH}_{4}^{+}>\mathrm{Ca}^{2+}$ $>\mathrm{Mg}^{2+}=\mathrm{H}^{+}$순이었으며, $\mathrm{Na}^{+}$와 $\mathrm{NH}_{4}{ }^{+}$성분이 전체 양이온 조성의 $61.2 \%$ 와 $56.5 \%$ 를 차지하였다. 음이온은 수원과 여 주 모두 $\mathrm{SO}_{4}{ }^{2-}>\mathrm{NO}_{3}{ }^{-}>\mathrm{Cl}^{-}$순으로 $\mathrm{SO}_{4}{ }^{2-}$ 가 $44.2 \%$ 와 $38.5 \%$ 를 차지하였다. 이는 Lee et al. (2009)과 Ko et al. (2010) 의 연구결과와 이온의 구성 차이가 없었으나 2009년 수원

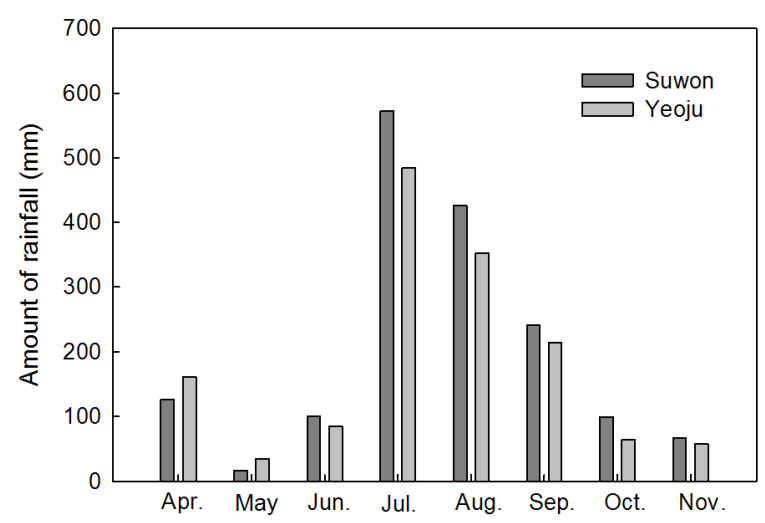

Fig. 1. Monthly rainfall in the sampling sites at Suwon and Yeoju in 2012. 
Table 1. Cation and anion composition ratios of rainwater collected at Suwon and Yeoju in 2012.

\begin{tabular}{lccccccccc}
\hline \hline \multirow{2}{*}{ Region } & \multicolumn{9}{c}{ Cations (\%) } \\
\cline { 2 - 10 } & $\mathrm{NH}_{4}{ }^{+}$ & $\mathrm{Ca}^{2+}$ & $\mathrm{K}^{+}$ & $\mathrm{Mg}^{2+}$ & $\mathrm{Na}^{+}$ & $\mathrm{H}^{+}$ & $\mathrm{NO}_{3}{ }^{-}$ & $\mathrm{SO}_{4}{ }^{2-}$ & $\mathrm{Cl}^{-}$ \\
\hline Suwon & 24.3 & 11.5 & 20.6 & 4.5 & 36.9 & 2.2 & 35.3 & 44.2 & 20.5 \\
Yeoju & 25.0 & 11.4 & 27.3 & 2.4 & 31.5 & 2.4 & 35.8 & 38.5 & 25.7 \\
\hline
\end{tabular}
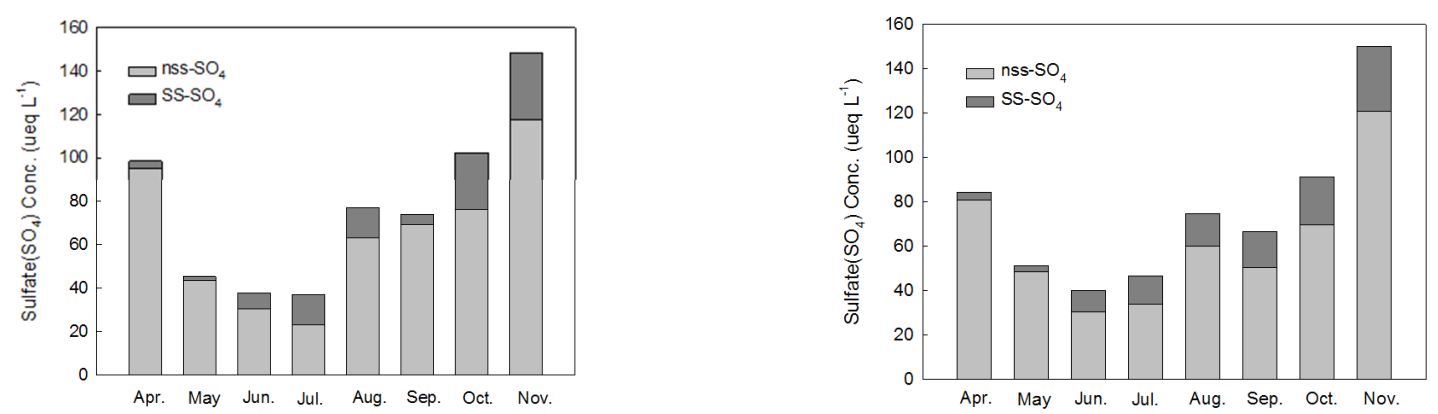

Fig. 2. Monthly changes of sulfate contents of rainwater collected at Suwon (left) and Yeoju (right) in 2012.
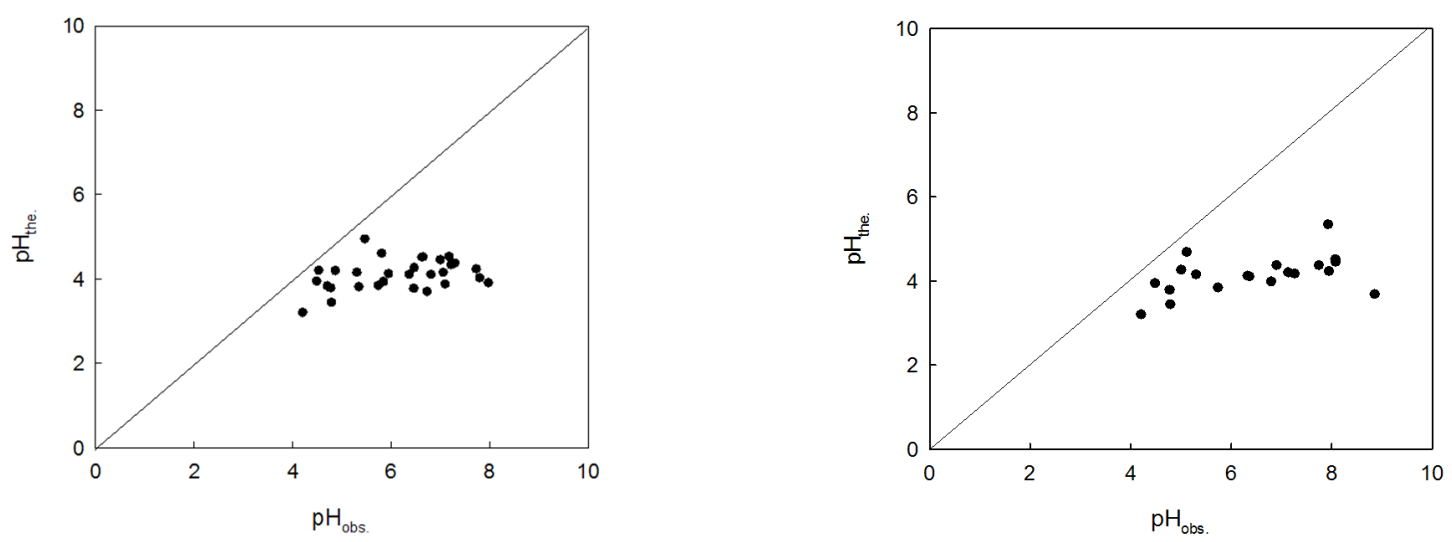

Fig. 3. Comelation between $\mathrm{pH}_{\text {obs }}$ (observational $\mathrm{pH}$ ) and $\mathrm{pH}_{\text {the. }}$ (theoretic $\mathrm{pH}$ ) of rainwater collected at Suwon (left) and Yeoju (right) in 2012. $\mathrm{pH}_{\text {the }}$ (theoretic acidity: $-\log \left(\left[\mathrm{H}^{+}\right]+\left[\mathrm{NH}_{4}{ }^{+}\right]+\left[\mathrm{Ca}^{2+}\right]\right)$.
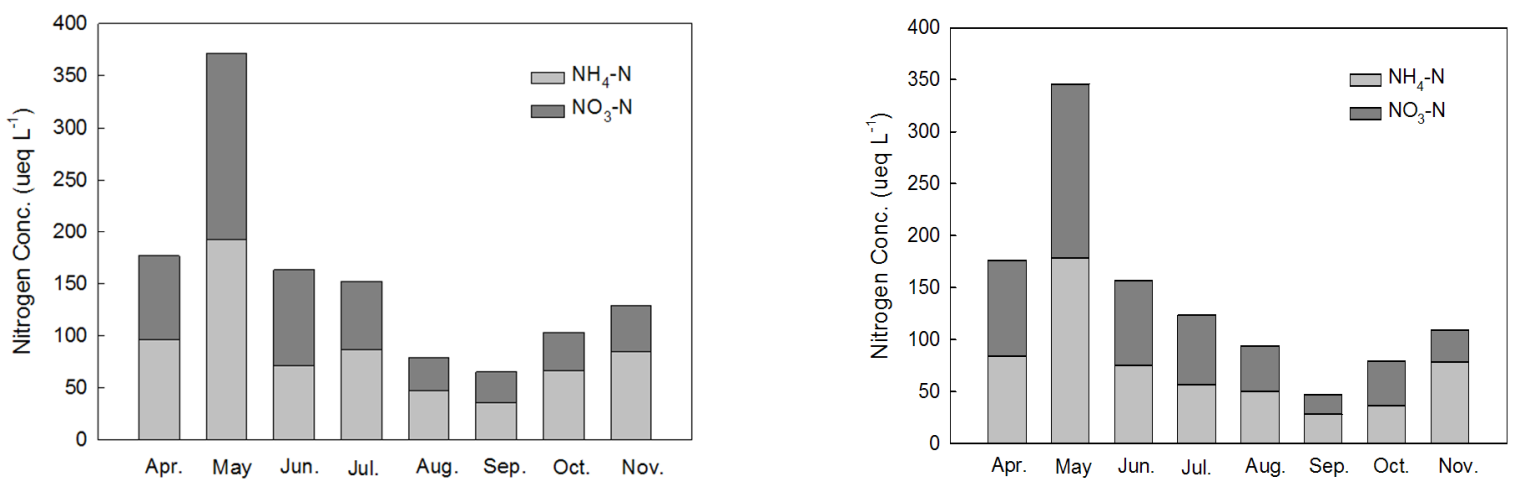

Fig. 4. Monthly changes of nitrogen content of rainwater collected at Suwon (left) and Yeoju (right) in 2012.

지역 강우의 양이온 구성 (Ko et al., 2010)과 2010년 수원 지역 강우의 양이온 구성 (Kim et al., 2013)과 비교할 때, $\mathrm{H}^{+}$의 구성 비율이 $\mathrm{Ca}^{2+}$ 보다 상대적으로 낮아졌다.

조사기간 중 월별 강우의 sulfate 함량과 $\mathrm{NSS}_{-} \mathrm{SO}_{4}^{2-}$ (Non-Sea Salt sulfate) 함량 변화는 Fig. 2와 같다. 인위적 인 발생원에서 배출된 $\mathrm{NSS}-\mathrm{SO}_{4}{ }^{2-}$ 는 sulfate 농도 중 해염에
서 기인된 부분을 제외한 농도로 $\mathrm{NSS}-\mathrm{SO}_{4}{ }^{2-}=\left[\mathrm{SO}_{4}{ }^{2-}\right]-$ $\left[\mathrm{Na}^{+}\right] \times 0.121$ 로 계산되었다. $\mathrm{Na}^{+}$는 해염 이외의 인위적인 발생원이 없고 해염입자의 조성이 해수의 조성과 일치한다 는 가정 하에 지표물질로 사용하였다 (Christian, 1963; Fujita et al., 2000). 계수 0.121은 해수의 $\left[\mathrm{Na}^{+}\right] /\left[\mathrm{SO}_{4}{ }^{2-}\right]$ 의 당량비이다. 
Table 2. Monthly changes of ion contents at Suwon and Yeoju in 2012.

\begin{tabular}{|c|c|c|c|c|c|c|c|c|c|c|}
\hline \multirow{2}{*}{ Month } & \multicolumn{5}{|c|}{ Suwon } & \multicolumn{5}{|c|}{ Yeoju } \\
\hline & $\mathrm{T}-\mathrm{N}$ & $\mathrm{SO}_{4}{ }^{2-}$ & $\mathrm{Ca}^{2+}$ & $\mathrm{K}^{+}$ & $\mathrm{Mg}^{2+}$ & T-N & $\mathrm{SO}_{4}{ }^{2-}$ & $\mathrm{Ca}^{2+}$ & $\mathrm{K}^{+}$ & $\mathrm{Mg}^{2+}$ \\
\hline & \multicolumn{10}{|c|}{ - } \\
\hline Apr. & 2.40 & 5.25 & 1.29 & 0.39 & 0.37 & 2.14 & 3.06 & 0.76 & 0.42 & 0.27 \\
\hline May & 1.55 & 2.31 & 0.69 & 0.31 & 0.34 & 1.55 & 2.11 & 0.69 & 0.21 & 0.14 \\
\hline Jun. & 1.83 & 5.52 & 0.46 & 0.18 & 0.21 & 1.40 & 1.52 & 0.66 & 0.18 & 0.12 \\
\hline Jul. & 5.28 & 8.80 & 0.61 & 1.39 & 0.19 & 3.50 & 11.04 & 0.53 & 1.11 & 0.18 \\
\hline Aug. & 2.15 & 16.91 & 0.64 & 8.00 & 0.16 & 2.23 & 8.36 & 0.40 & 2.07 & 0.12 \\
\hline Sep. & 1.02 & 5.62 & 0.45 & 0.19 & 0.14 & 0.91 & 5.16 & 0.32 & 0.14 & 0.10 \\
\hline Oct. & 0.45 & 3.33 & 0.38 & 1.01 & 0.12 & 0.30 & 2.62 & 0.33 & 0.03 & 0.11 \\
\hline Nov. & 0.91 & 3.97 & 0.68 & 0.32 & 0.23 & 0.15 & 0.36 & 0.34 & 0.01 & 0.09 \\
\hline Total & 15.6 & 51.7 & 5.20 & 11.8 & 1.76 & 12.2 & 34.2 & 4.03 & 4.17 & 1.13 \\
\hline
\end{tabular}

조사기간 중 강우 중에 용존해 있는 sulfate의 전체 평균 함량은 수원 77.6 과 여주 $75.6 \mu \mathrm{eq} \mathrm{L}{ }^{-1}$ 이었는데, 이는 2009 년 수원지역의 sulfate 평균 함량 (Ko et al., 2010)과 2010 년 수원지역의 sulfate 평균 함량 (Kim et al., 2013)과 비교 할 때 상대적으로 낮아졌다. 수원과 여주 모두 11 월에 각각 139.0과 $150.1 \mu \mathrm{eq} \mathrm{L}{ }^{-1}$ 으로 연중 가장 높게 나타났으며 총 sulfate 함량 중 NSS- $\mathrm{SO}_{4}{ }^{2-}$ 함량은 수원 83\%과 여주 $82 \%$ 로 나타났다. 이러한 결과는 강우 중에 함유된 sulfate의 대부 분이 인위적인 발생원에서 기인된 것임을 의미하며, 88 $89 \%$ 를 차지했던 기존의 결과(Lee et al., 2004; 2009 , Ko et al., 2010)와 비교할 때 비슷한 수준으로 나타났다.

조사지역 강우의 산성도 중화를 평가하기 위하여 측정 $\mathrm{pH}$ 와 기존 보고 (Galloway et al., 1987)에 의해 구한 이론 $\mathrm{pH}$ 값 ( $\mathrm{pH}_{\text {the. }}$ )를 비교한 결과는 Fig. 3과 같다. 이 1:1 직선 의 오른쪽으로 치우칠수록 중화가 많이 일어났음을 의미하 는데 본 연구 결과 조사기간 중 수원과 여주지역에 내린 강 우에서 중화가 일어났음을 보였다. 그러나 강우의 $\mathrm{pH}_{\text {the. }}$ 비 교에 있어 수원지역의 강우가 여주 강우에 비하여 가운데에 위치하여 중화가 덜 일어났음을 보였다.

강우를 통한 질소 부하량 평가는 농업생태계의 대기침적 을 통한 비점오염 평가에도 중요하다 (Lee et al., 2009). 강 우 중 월별 암모늄태 및 질산태 질소의 강우량 가중 평균 농 도 (Volume-weighted mean concentration)를 분석한 결과 는 Fig. 4 와 같다. 총 무기태 질소의 강우량 가중 평균 농도 는 수원과 여주지역 모두 다른 시기에 비해 5 월에 각각 371 와 $346 \mu \mathrm{eq} \mathrm{L} \mathrm{L}^{-1}$ 로 가장 높았으며, 9 월에 각각 65 와 $47 \mu \mathrm{eq}$ $\mathrm{L}^{-1}$ 로 가장 낮았다가 10 월부터 다시 증가하는 경향이었다. Arsene et al. (2007)은 대부분의 강우 중 양이온 농도는 시 기별로 변이가 컸는데 암모늄태 질소는 영농기에 가장 높은 경향을 보인다고 하여 본 연구결과와 비슷하였다. 그러나 Budhavant et al. (2011)의 연구결과에 의하면 비영농기 (11 $\sim 3$ 월)에 강우 중 암모늄태 질소의 농도가 높았는데 이는 농업활동에 의한 것보다는 사람이나 동물의 배설물 때문으 로 보고하였다.

조사기간 동안 수원과 여주에서 월별 전체 이온들의 부 하량을 평가한 결과는 Table 2 와 같다. 수원과 여주 두 지역 모두 월별 비슷한 변화양상을 보였으나 이온들의 부하량에
서는 수원이 여주보다 훨씬 많았다. 이는 수원이 여주보다 강우량이 많아 전체 부하량이 많은 것으로 생각된다.

강우에 의해 부하되는 총질소량은 강우량이 가장 많은 7 월에 수원과 여주가 각각 5.28 과 $3.50 \mathrm{~kg} \mathrm{ha}{ }^{-1}$ 으로 가장 많 았으나 대부분은 주변 수계로 바로 유입되어 작물의 이용은 많지 않을 것으로 생각된다. 강우 중에 존재하는 황산이온 은 석유나 석탄 또는 생물체를 태울 때 황이 산화되어 배출 된 가스인 이산화황 $\left(\mathrm{SO}_{2}\right)$ 으로부터 발생된다. 수원과 여주 지역에서 황산이온이 강우를 통하여 토양에 공급되는 양은 여주의 6 월과 11 월을 제외하고는 수원과 여주 모두 매월 2 $\mathrm{kg} \mathrm{ha}^{-1}$ 이상으로 나타났으며 특히 강우량이 많은 수원 8월 과 여주 7 월에 가장 많았다. 강우성분의 이온조성의 근원 파악 연구 (Galloway et al., 1987)에서 강우 성분 중 $\mathrm{Na}^{+}$와 $\mathrm{Mg}^{2+}$ 는 주로 해염에서 기인되며 $\mathrm{Ca}^{2+}$ 는 토양과 건축자재가 주 발생원임을 밝혔다. 주 영농기인 4 11월 동안 작물에 영양원으로 사용될 수 있는 이온인 $\mathrm{SO}_{4}{ }^{2-}, \mathrm{Ca}^{2+}, \mathrm{K}^{+}, \mathrm{Mg}^{2+}$ 는 수원과 여주 각각 $51.7,5.20,11.8,1.76 \mathrm{~kg} \mathrm{ha}^{-1}$ 과 34.2 , $4.03,4.17,1.13 \mathrm{~kg} \mathrm{ha}^{-1}$ 이 공급되는 것으로 나타났다. 수원 지역의 이온들의 부하량은 2009년 (Ko et al., 2010)과 2010 년 (Kim et al., 2013) 이온들의 부하량과 비슷한 수준이었 다. 여주에 비해 수원에서 이온성분들의 부하량이 많은 것 은 수원이 여주에 비해 자동차 등 사람의 활동이 많은 도시 인근에 위치하여 더 많은 무기성분이 강우에 포함되어 있는 것으로 생각된다.

\section{References}

American Public Health Association. 1998. Standard Methods for Examinations of Water and Wastewater. 20th edition. Washington D.C., USA.

Arsene, C., R.I. Olariu, and N. Mihalopoulos. 2007. Chemical composition of rainwater in the northeastern Romania, Iasi region (2003-2006). Atmospheric Research, 41:9452-9467.

Budhavant, K.B., P.S.P. Rao, P.D. Safai, K. Ali. 2011. Influence of local sources on rainwater chemistry over Pune region, India. Atmospheric Research, 100:121-131. 
Charron, A., H. Plaisance, S. Sauvage, P. Coddeville, J.C. Galloo, and R. Guillerm. 2000. A study of the source-receptor relationships influencing the acidity of precipitation collected at a rural site in France. Atmospheric Environment. 34: 3665-3674.

Cheng, M.C., C.F. You, F.J. Lin, K.F. Huang, and C.H. Chung. 2011. Sources of $\mathrm{Cu}, \mathrm{Zn}, \mathrm{Cd}$ and $\mathrm{Pb}$ in rainwater at a subtrophical islet offshore northern Taiwan. Atmospheric Environment. 39:6175-6183.

Christian, E.J. 1963. Air chemistry and radioactivity. Academic Press. England. p.327-330.

Chudaeva, V.A., S.G. Urchenko, O.V. Chudaev, K. Sugimory, M. Mastsuo, and A. Kuno. 2006. Chemistry of rainwaters in the south Pacific area of Russia. J. Geochem. Explor. 88:101-105.

Contardi, V., E. Franceschi, S. Bosio, G. Zanicchi, D. Palazzi, L. Cortessogno, and L. Gaggero. 2000. On the conservation of architectural artistic handwork of the 'Pietra di Finale'. J. of Cultural Heritage. 2:83-90.

Cronan, C.S. and C.L. Schofield. 1979. Aluminum leaching response to acid precipitation: Effects on high-elevation watersheds in the Northeast. Science. 204:304-306.

Fujita, S.I., A. Takahashi, J.H. Weng, L.F. Huang, H.K. Kim, C.K. Li, F.T. Huang, and F.T. Jeng. 2000. Precipitation chemistry in East Asia. Atmospheric Environment. 34:525537.

Galloway, J.N., D. Zhao, J. Xiong, and G.E. Likens. 1987. Acid rain: China, United States, and a remote area. Science. 236:1559-1562.

Kim, M.K., J.S. Lee, G.B. Jung, B.G. Ko, S.I. Kwon, M.Y. Kim, K.H. So, and S.G. Yun. 2013. Chemical characterization of rainwater over Suwon region during farming and non-farming periods. Journal of Agricultural Chemistry and Environment. 2:1-7.

Ko, B.G., M.K. Kim, J.S. Lee, G.Y. Kim, S.J. Park, S.I. Kwon, G.B. Jung, and D.B. Lee. 2010. Chemical properties and nutrient loadings of rainwater during farming season. Korean J. of Soil. Sci. Fert. 43:578-583.

Lee, J.S., M.K. Kim, S.J. Park. C.M. Choi, and T.W. Jung. 2009. Neutralization of acidity and ionic composition of rainwater in
Taean. Korean J. of Soil. Sci. Fert. 5:336-340.

Lee, J.S., G.B. Jung, J.D. Shin, and J.H. Kim. 2004. Chemical properties of rainwater in Suwon and Taean area during farming season. Korean Journal of Agricultural and Forest Meteorology. 6:250-255.

Lee, J.S., Y.K. Jung, and K.S. Lee. 1999. Chemical composition of rainwater in Taean area. Kor. J. Environ. Agric. 18:204-208.

Ministry of Environment. 2008. Korea standard methods for water quality. Ministry of Environment. Goacheon. Korea.

Murdoch, P.J., J.S. Baron, and T.L. Miller. 2000. Potential effects of climate change on surface-water quality in North America. J. of the American Water Resources Association. 36:347-366.

Okochi, H., H. Kameda, S. Hasegawa, N. Saito, K. Kubota, and M. Igawa. 2000. Determination of concrete structures by acid deposition - An assessment of the role of rainwater on deterioration by laboratory and field exposure experiments using mortar specimens. Atmospheric Environment. 34:2937-2945.

Park, S.U., Y.H. Lee, and H.J. In. 2000. Estimation of wet deposition of sulfate using routinely available meterological data and air-monitored data in Korea. Atmospheric Environment. 34:3249-3258.

Peart, M.R. 2000. Acid rain, storm period chemistry and their potential impact on stream communities in Hong Kong. Chemosphere. 41:25-31.

Rinallo, C. 1992. Effects of acidity of simulated rain on the fruiting of 'summerred' apple trees. J. of Environmental Quality. 21:61-68.

Scorer, R.S. 1994. Long distance transport. Acid rain, p.1-34. Gordon \& Breach Science Publishers. USA.

Wang, T.J., F. Jiang, S. Li, and Q. Liu. 2007. Trends in air pollution during 1996-2003 and cross-border transport in city clusters over the Yangtze River Delta Region of China. Terr Atmos Ocean Sci 5:995-1009.

Wang, C., P. Guo, G. Han, X. Feng, P. Zhang, and X. Tian. 2010. Effect of simulated acid rain on the litter decomposition of Quercus acutissima and Pinus massoniana in forest soil microcosms and the relationship with soil enzyme activities. Science of The Total Environment. 408:2706-2713. 